\title{
ENTREVISTA COM MARIANA ALDRIGUI CARVALHO
}

Mariana Aldrigui Carvalho possui Doutorado em Geografia Humana pela FFCLH/USP, Mestrado em Ciências da Comunicação e graduação em Turismo pela ECA/USP. Atua como professora e pesquisadora do corpo docente da EACH/USP há 12 anos. É presidente do Conselho de Turismo da Fecomércio/SP e possui 25 anos de experiência em diferentes empresas do turismo brasileiro. Participa ativamente de grupos internacionais que se dedicam ao debate sobre turismo e seus papéis econômico e social. Desenvolve análises sobre o turismo em São Paulo e no Brasil, com destacado interesse na área de políticas públicas, educação e desenvolvimento do turismo

\section{Entrevista realizada por Dores Cristina Grechi}

Entre Lugar: Qual o principal objetivo do Conselho de Turismo da Federação do Comercio de Bens, Serviços e Turismo do Estado de São Paulo (Fecomércio-SP) e como tem planejado e executado sua atuação?

Mariana Aldrigui Carvalho: O Conselho de Turismo da FecomercioSP elabora análises e pesquisas sobre o setor de turismo no Brasil, a partir da colaboração dos conselheiros e da atuação da equipe de economistas e advogados que o assessoram, e procura identificar oportunidades de desenvolvimento para o turismo brasileiro, especialmente a partir do estado de São Paulo.

Entre Lugar: Você pode nos contar sobre a pesquisa Indicador de Turismo Panrotas?

Mariana Aldrigui Carvalho: O Indicador de Turismo Panrotas-FecomercioSP é o resultado de uma parceria entre estas duas instituições com o objetivo de coletar impressões sobre o setor ou situações que o influenciam, e tratar os dados com rigor metodológico para poder compara-los a outras pesquisas da FecomercioSP. Até o momento foram rodadas duas edições do Indicador - a primeira falava da expectativa para 2018, e a segunda sobre a percepção do setor em relação à elevação da taxa de câmbio. A terceira deve sair logo após o primeiro turno. 
Entre Lugar: Porque a senhora afirmou, em uma matéria para folha de São Paulo, que “não existe política de turismo no país"?

Mariana Aldrigui Carvalho: Uma política de turismo é um conjunto de diretrizes que orientam a atividade no país. Em 15 anos de Ministério de Turismo, já tivemos 13 ministros, a maioria deles vinculados ao MDB (antigo PMDB), cujo papel foi usar o cargo para "administrar" a base aliada nos votos de interesse da presidência da república. A sequência de documentos que foram divulgados pelo Ministério com os nomes de Plano Nacional de Turismo são uma coleção de sugestões baseadas em senso comum, sem relação com o orçamento da pasta e menos ainda com programas específicos do governo. Em nenhum deles, há indicação clara de como se chegaria ao volume de turistas estrangeiros desejado ou ao número de empregos previstos. Tanto é que nunca se atingiu o planejado. Mais preocupante ainda é ler que o Brasil seria a $3^{\text {a }}$ economia de turismo do mundo. Para quem trilhou carreira na pesquisa em turismo isso é uma grande ofensa, pois demonstra o desprezo dos gestores públicos aos pesquisadores que há anos se dedicam à compreensão da atividade no país e de sua representatividade nos fluxos mundiais.

Entre Lugar: Como professora da área de políticas de turismo, qual a sua opinião sobre os principais entraves para a gestão do turismo em nível federal e estadual?

Mariana Aldrigui Carvalho: O grande entrave segue sendo a existência da pasta para acomodação de aliados, sem vínculo ao orçamento e sem relação com o projeto de governo, seja ele qual for. Na sequência, a nomeação de líderes que, além de não entender nada do setor, se cercam de pessoas que trazem sugestões diretamente de livros editados no século passado. Ano após ano, mandato após mandato, os textos são copiados, as expressões repetidas ad infinintum, e resultados não aparecem. Naturalmente, isso não é exclusividade do turismo - várias áreas têm líderes que nada entendem, mas as bancadas parlamentares e a pressão popular ajudam na sugestão de pautas e de projetos. No caso de turismo, os projetos para as pastas beiram o ridículo. 
Entre Lugar: Como os cursos de turismo podem auxiliar na discussão, elaboração e análise das políticas de turismo? Há alguma instância nacional e os cursos participam de forma organizada e transparente?

Mariana Aldrigui Carvalho: Os cursos de turismo sofrem, neste momento, de uma queda significativa na demanda. A produção de pesquisas sobre o turismo brasileiro que sejam propositivas e tratem de pensar o médio e o longo prazo é quase inexistente. São muitos estudos de caso e descrições qualitativas para poucas propostas de fato. Além disso, professores se sobrecarregam com as rotinas educacionais para conseguir se atualizar e perceber o que de fato se passa no país. Discutir política não é ler sobre política, mas ajustar o olhar para o que cabe nas brechas das discussões consideradas mais importantes para o país. É aprender a fazer concessões e conseguir a simpatia de outros setores para que incluam turismo em seus projetos maiores. Os egressos de turismo entendem pouco (ou nada) de análise financeira, de retorno de investimentos, de como pensar um projeto que seja - ao mesmo tempo - economicamente viável e politicamente adequado. E leem pouco, e escrevem mal. Com isso, se dedicam a pensar e atuar nas funções operacionais. Minha leitura é que o curso, como é hoje, perderá sentido. Quanto mais rápidas forem as instituições que reformularem suas matrizes e pensarem outra formação para o turismo, melhores serão os resultados para o mercado de trabalho e para a elaboração de políticas.

Sobre a representação, a participação das entidades que se dizem representativas de cursos e egressos é figurativa. Nada representam de fato, apenas participam de reuniões e levantam suas bandeiras envelhecidas e sem conexão com a realidade.

Entre Lugar: Se a senhora fosse responsável pela organização política de turismo do país, quais as diretrizes e princípios fundamentais levaria em conta de forma estratégica e inegociável?

Mariana Aldrigui Carvalho: Buscaria trabalhar pelo esclarecimento dos pares - para que todos estivessem falando da mesma coisa, com as mesmas referências. Eventualmente, sugeriria que o Turismo deixasse de ser uma pasta específica, e passasse a ser uma diretoria ou uma secretaria ligada ao Desenvolvimento Econômico (do país, de um estado, de uma cidade). Teria clareza do orçamento e das limitações políticas do momento - para não criar expectativas impossíveis, e investiria pelo menos $30 \%$ deste 
orçamento em pesquisas e mapeamentos para indicar as melhores oportunidades de investimento. A maior parte do tempo seria dedicada a incluir temas de turismo nos grandes projetos - transportes, infraestrutura, educação, atração de investimento estrangeiro, negociações bilaterais. E buscaria qualificar gestores públicos sobre o quão fácil é incluir turismo na discussão e nos projetos, para criar uma cultura de conhecimento sobre o setor que sobrevivesse à minha gestão.

Entre Lugar: Professora, a senhora tem um estilo único de escrever, as vezes bem desafiador. Como na carta a Guilherme Paulus sobre a situação de fechamento de muitos cursos de turismo. A senhora poderia manifestar sua opinião sobre o assunto do mercado de trabalho para o nosso leitor? Uma curiosidade, ele respondeu sua carta aberta enviada a ele em julho de 2017 ?

Mariana Aldrigui Carvalho: Sim, a carta foi respondida e pode ser lida aqui http://blog.panrotas.com.br/ensinando-turismo/index.php/2017/08/02/guilherme-paulusresponde/

Não foi a resposta que eu desejava, mas pelo menos foi um passo para mais esclarecimentos. O mercado de turismo é sedutor, e muita gente se interessa por ele mas isso pressiona os salários para baixo, ou seja, as chances de termos posições bem remuneradas é sempre mais baixa. Outro ponto é a distância cada vez maior entre a sala de aula e a realidade - o aluno tem o diploma mas quase nada do que aprende é útil nas empresas que hoje contratam, portanto mais um motivo alegado para pagar pouco. Os bons profissionais se cansam de ser desmerecidos e trocam de área - por mais reconhecimento e maior remuneração. Ficam os menos ágeis, e isso é um círculo vicioso.

Novamente - quanto antes os cursos revisarem seu foco e se alinharem a tendências fortes, melhor será a percepção externa e maior a empregabilidade do egresso. Ou seja sim, sou bastante pessimista com o atual cenário dos cursos - acho fracos, descomprometidos e fadados ao desaparecimento. 
Entre Lugar: Para o profissional que está em formação neste momento, seja na graduação ou na pós-graduação que orientações a senhora daria?

Mariana Aldrigui Carvalho: Em letras maiúsculas - FINANÇAS. Faça cursos para entender o básico de Administração Financeira e Revenue Management. Faça um bom curso de elaboração e gestão de projetos (com componente financeiro). Há vários deles online, alguns grátis, e essas competências farão muita diferença nos processos seletivos. E crie espaço para consumo de cultura - filmes, séries, livros, podcasts, mostras, shows. Especialistas em neurociência já vem anunciando há tempos que quanto mais nos expomos a ideias e sensações diferentes, mais somos capazes de aprender coisas novas e entender as mudanças.

Entre Lugar: Na sua opinião quais as principais tendências globais que irão impactar o mercado turístico nos próximos anos?

Mariana Aldrigui Carvalho: Mudança de valor nos mais jovens - menos bens, mais experiências - viajar sempre que possível, o que implica modificar o jeito de viajar, a forma de comprar viagens e de viver o destino. Uso intenso de tecnologia pelo turista; necessidade de entender o processo de decisão para posicionar produtos e serviços; interação multi-plataformas e rastros digitais determinando o posicionamento das empresas.

Sustentabilidade em todas as suas expressões, valorização da diversidade.

E sempre - atenção aos clientes em todas as etapas do processo de escolha, viagem e retorno.

Entre Lugar: A senhora poderia contar um pouco sobre seu curso de aperfeiçoamento sobre "Tourism Policy”, na University of Surrey, Inglaterra? Qual o grande diferencial desta experiência e como ela ajuda nas suas aulas e na sua atuação na FECOMERCIO?

Mariana Aldrigui Carvalho: Ao longo dos meses em que morei em Surrey, convivi com o Prof. David Airey, que eu considero o maior pesquisador do tema para a Europa. Profundo conhecedor dos entraves ao desenvolvimento do turismo, especialmente em função das questões da Zona do Euro, ele me permitiu mergulhar em sua biblioteca 
pessoal e tivemos conversas inesquecíveis sobre o turismo no mundo. Tanto o Prof. Airey como os meus colegas que faziam mestrado e doutorado na ocasião tinham profundo domínio sobre o tema e traziam ao debate questões muito densas - o que nos permitiu construir excelentes relações profissionais de troca e de confiança. Eu diria que todas as minhas experiências foram e são importantes na minha atuação - eu procuro colocar sempre em dúvida aquilo que eu sabia ontem e vejo se ainda é válido, se faz sentido para quem está me ouvindo, se é possível construir exemplos atuais e vinculados ao que o aluno já viveu. Penso que descer de um pedestal inexistente, em que muitos professores se colocam - e ouvir o outro - é o passo inicial para construir conhecimento coletivamente. Os dez meses no Conselho de Turismo tiveram esta marca. E os doze anos na USP, bem como os anos anteriores em outras instituições também.

Entre Lugar: Professora, a senhora também pesquisa o assunto hospitalidade e cidades, a senhora poderia apresentar ao nosso leitor seu ponto de vista sobre esta temática, seus aspectos gerais e assuntos que merecem mais atenção dos pesquisadores nesta seara?

Mariana Aldrigui Carvalho: há uma relação intrínseca entre hospitalidade em cidades e política de turismo, mas ainda não evidente no Brasil. Neste caso, é necessário entender que não faz sentido atrair visitantes ou pensar turismo se as condições de vida no local não estão em seu melhor - segurança, limpeza, qualidade nos serviços públicos, acolhimento e qualidade de vida para o morador. A cidade que trata seu morador de forma digna é interessante para o turista. Querer desenvolver turismo sem resolver antes sérias questões de base na gestão pública resultará no que vemos hoje equívocos e mais equívocos. Para quem se dispõe a atuar com esta temática, cabe pensar de que forma a gestão pública pode colocar o morador no centro das decisões. Moradores orgulhosos são embaixadores sempre - veja o caso emblemático da Bahia e do Ceará, mais recentemente (positivamente) e da tristeza que acomete o Rio de Janeiro e como o descaso com a população afetou drasticamente os resultados do turismo. Não adianta ser lindo. Tem que parecer seguro, tem que ser convidativo. 
Entre lugar: Como a senhora enxerga a relação entre a Universidade (cursos de graduação e pós-graduação) e as esferas como Fecomércio, o programa GTTP (Global Travel and Tourism Partnership) e WTM Latin America das quais a senhora faz parte? Mariana Aldrigui Carvalho: Todos os convites que recebo são fruto da busca de oportunidades para posicionamento profissional de meus alunos de graduação. Desde que assumi o papel de supervisora de estágios na unidade em que atuo, passei a acompanhar diariamente as notícias do setor, por meio de portais específicos. Investi muito tempo e recursos na participação de eventos para conhecer pessoas e estruturar projetos conjuntos que resultassem no reconhecimento da formação e do curso (que, ainda, é muito desconhecido). Ao treinar professores de escolas públicas utilizando o conteúdo da GTTP, ampliamos o alcance da formação em turismo para diferentes níveis da educação pública gratuita. Coordenando painéis de turismo sustentável na WTM Latin America, colocamos diferentes profissionais para falar com quem pode se interessar pelo tema e fazer algo de verdade, para mudar o que vimos acontecer. Sempre que possível, alocamos estudantes como monitores, estagiários e colaboradores neste evento e em outros similares. A atuação na FecomercioSP envolve fundamentalmente a coordenação de pesquisas que são disponibilizadas gratuitamente para toda a sociedade, e com isso colaboramos para que os temas importantes do turismo ocupem mais espaço na imprensa e nos eventos específicos. Sou pesquisadora o tempo todo, e professora quando me permitem, portanto o tempo todo estarei trabalhando para indicar as melhores rotas aos meus alunos.

Entre Lugar: Como a senhora enxerga o cenário da Pós-Graduação em Turismo no país?

Mariana Aldrigui Carvalho: Como não tenho envolvimento com programas de pósgraduação no Brasil, não posso comentar com propriedade. Acompanho as publicações internacionais e o avanço de algumas áreas, mas não vejo autores brasileiros colaborando com novas leituras ou proposições teóricas de peso. Nos periódicos científicos, lê-se sempre mais do mesmo, portanto não saberia identificar quem tem feito um trabalho relevante. Por outro lado, há muitos convites para pesquisas fora do 
país, e acredito que em breve teremos brasileiros integrando times qualificados para analisar o turismo mundial.

Entre lugar: Na sua opinião quais são os temas mais pertinentes para a pesquisa científica em turismo?

Mariana Aldrigui Carvalho: Todos os temas são pertinentes, de verdade. Se houver o devido rigor metodológico, com revisões de literatura e análise que contemple o atual estado da arte em diferentes idiomas, os trabalhos serão bem feitos. Mas enquanto as referências forem exclusivamente brasileiras e do século passado, não avançaremos. Os temas que me agradam envolvem métricas, comparações e novas abordagens. Ser capaz de falar do turismo em relação a outras atividades, para que se possa ter uma perspectiva correta e realista é algo que está em falta.

Entre Lugar: Para finalizar, como a senhora vê a interface entre turismo e geografia?

Mariana Aldrigui Carvalho: Embora eu não concorde que o Turismo seja uma das leituras da Geografia, como alguns pesquisadores apregoam, eu entendo que o conhecimento organizado pelos geógrafos é base para a construção das análises de turismo. As cidades, as conexões, os deslocamentos... a Geografia nos permite entender muito e, como consequência, trazer as reflexões da economia, da gestão, do comportamento do consumidor, da relação com a tecnologia para ampliar o entendimento do turismo. Também não concordo que o Turismo seja considerado uma ciência - não o é. Mas é, sim, uma atividade realizada pelas pessoas que chama a atenção de diferentes áreas do conhecimento, e com a contribuição de todos, poderemos elaborar documentos que orientem os governos no sentido de, efetivamente, ampliar as oportunidades para todos, preservando nossos recursos e gerando mais empregos e renda para os brasileiros. 